Proceedings

\title{
The impact of the average temperature, humidity, wind speed, altitude, and population density on daily COVID-19 infections' evolution
}

\author{
Rachid LAGTAYI ${ }^{1,3, *}$, Lamya LAIRGI ${ }^{2}$, Abdelmajid DAYA ${ }^{2}$ and Ahmed KHOUYA ${ }^{3}$
}

1 Department of Sciences, Industrial and Civil Technologies, Team of sciences and advanced technologies, National School of Applied Sciences, Tetouan, Abdelmalek Essaadi university, Morocco; rachid.lagtayi1@etu.uae.ac.ma

2 Department of Physics, Laboratory of M3ER-, FSTE, Moulay Ismail University, Morocco; 1.lairgi@edu.umi.ac.ma; a.daya@fste.umi.ac.ma

3 Department of Electrical and Industrial Engineering, National School of Applied Sciences, Tangier, Abdelmalek Essaâdi University, Morocco; akhouya@uae.ac.ma

* Correspondence: rachid.lagtayi1@etu.uae.ac.ma; Tel.: 00212659115006

Publisher's Note: MDPI stays neutral with regard to jurisdictional claims in published maps and institutional affiliations.

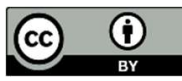

Copyright: $\odot 2021$ by the authors. Submitted for possible open access publication under the terms and conditions of the Creative Commons Attribution (CC BY) license (http://creativecommons.org/licenses/by/4.0/).

\begin{abstract}
The aim of this study is to investigate the impact of climate conditions, altitude, and population density on the daily COVID-19 infections' evolution. For an average wind speed greater than $25 \mathrm{~km} / \mathrm{h}$, the number of daily COVID-19 infections is slightly decreased with a rate of $10 \%$, while the temperature, humidity and altitude factors didn't affect its evolution, furthermore, the population density strongly affects its progression with an approximate rate of $90 \%$. Finally, we have proposed a mathematical model to estimate the evolution of COVID19 infections over time by taking into consideration simultaneously the wind speed and the population density effects.
\end{abstract}

Keywords: COVID-19 infections; Climate conditions; Altitude; Population density; Mathematical model

\section{Introduction}

Historically, between 1918 and 1920, the Great Influenza Pandemic which is known as the Spanish Flu caused 39 million of deaths which means $2 \%$ of the world population [1]. Moreover, other respiratory pandemics have appeared such as Swine Flu, SARS, Ebola, MERS and lately the COVID-19 pandemic which is an infectious disease caused by a newly discovered coronavirus [1]-[4]. In December 2019, the city of Wuhan at Hubei province in China attracted the worldwide attention because of a new respiratory viral disease outbreak of an unknown cause. By Jan 7, 2020, Chinese scientists had isolated a novel coronavirus (COVID-19) from patients in Wuhan [5]. On the 10th of January 2020, 41 patients got infected by COVID-19, where 6 of them recovered, 7 in critical conditions and the rest of the patients were in a stable condition [6]. On 30th April 2020, the number of infections reached 3,090,445 with 217,769 deaths and 1,030,715 cases that have recovered [7].

Recently, because of the quick spread of COVID-19 pandemic around the globe, World Health Organization has announced a state of emergency which has put researchers and scientists from different fields in front of a big challenge in order to analyze and give the right responses about the mechanism of the evolution of this serious pandemic each from their own prospective, whereas, understanding how environmental parameters and population density factors affect the COVID-19

The 3rd International Electronic Conference on Environmental Research and Public Health 
spread [8]-[10], still a vital question that could help the global community to introduce the right solutions and invent new technologies to prevent and reduce COVID19 infections' progression.

The aim of this paper is to study the impact of the climate parameters (daily average temperature, daily average humidity and daily average wind speed), altitude and population density on the daily number of COVID-19 infections around six different cities: Casablanca (Morocco), New York (USA), Madrid (Spain), Lombardy Milan (Italy), Paris (France), Wuhan (China) between the 1st February and $25^{\text {th }}$ April, 2020. Consequently, we have proposed a mathematical model to estimate simultaneously the impact of wind speed factor and population density on daily COVID-19 contaminated cases.

\section{Materials and Methods}

The databases of the daily average temperature, humidity, and wind speed across the cities of Casablanca, New York, Madrid, Lombardy-Milan, Paris, Wuhan were collected between January $23^{\text {rd }}$ and April $25^{\text {th }}, 2020$. Moreover, we have determined the average altitude, average annual number of population and visitors plus the daily and cumulated COVID-19 infections' evolution around the six studied cities (Figures A1, A2 and A3 and Table 1 in Appendix A).

According to experimental epidemiologists' estimations, 95\% of patients had an estimated median incubation period of 4 to 5.1 days and $97.5 \%$ of them had symptoms of 11.1 days [18] Consequently, the duration between the day when a susceptible will be infected by COVID-19 virus and the day when its case could be detected is estimated to be 9 days. Thus, we can say that the climate parameters (Temperature: Ti, Humidity: Hi, Wind speed: Wi) at i day show their impacts on N(i+9) detected cases at $(\mathrm{i}+9)$ days.

We have classified the studied factors into two types of variables:

- Dependent variables: Daily temperature Ti, Daily humidity Hi and Daily wind speed Wi.

- Independent variables: Altitude, average annual population density. by:

We assume that the average annual population density is constant and given

$\mathrm{P}_{\text {total }}=\mathrm{P}_{\mathrm{s}}+\mathrm{P}_{\mathrm{t}}$

(1)

where, $P_{s}$ is the average annual population density in a city and $P_{t}$ is the average annual visitors' density across each city.

$\checkmark$ Before the lockdown: $\quad \mathrm{P}_{\text {total }}=\mathrm{P}_{\mathrm{s}}+\mathrm{P}$

$\checkmark$ After the lockdown: $\quad \mathrm{P}_{\text {total }}=\mathrm{P}_{\mathrm{s}}$

The average annual number of populations $\mathrm{N}(\mathrm{t})$ in a city could be presented as [19]:

$N(t)=S(t)+I(t)+R(t)$

where:

$S(t)$ : Number of susceptibles on day $(t)$.

$I(t)$ : Number of infected cases on day $(t)$.

$R(t)$ : Number of recovered patients on day $(t)$.

The variables $S(t), I(t)$ and $R(t)$ vary over time and they could be presented by a system of three differential equations as follow [20] :

$$
\left\{\begin{array}{l}
\frac{d S}{d t}=-a S(t) \cdot I(t) \\
\frac{d I}{d t}=a S(t) \cdot I(t)-b I(t) \\
\frac{d R}{d t}=b I(t)
\end{array}\right.
$$


where:

a: Expected amount of people an infected person infects per day $\left(\mathrm{a} \approx 1 / \mathrm{t}_{\mathrm{i}}\right)$.

b: The proportion of recovered patients per day $(b=1 / D)$, while $D$ is the approximate number of days when

patient will recover ( $D=14$ days in our estimations).

tip: The estimated average incubation period (equals 5.75 days in our study) in which an infected patient

could infect other susceptible.

\section{Results and Discussion}

The analysis of the impact of the average daily temperature, average daily humidity, and the average altitude (Figures B4, B5 and B6 in Appendix B) shows that these factors have no effect on daily COVID-19 infections' evolution.

In the Figure 6, we note that for an average wind speed more than $25 \mathrm{Km} / \mathrm{h}$, the amplitude of daily confirmed infections is reduced across the studied cities, which means that the wind speed factor slightly impacts the daily of COVID-19 infections' evolution compared to the other climatic parameters under study.
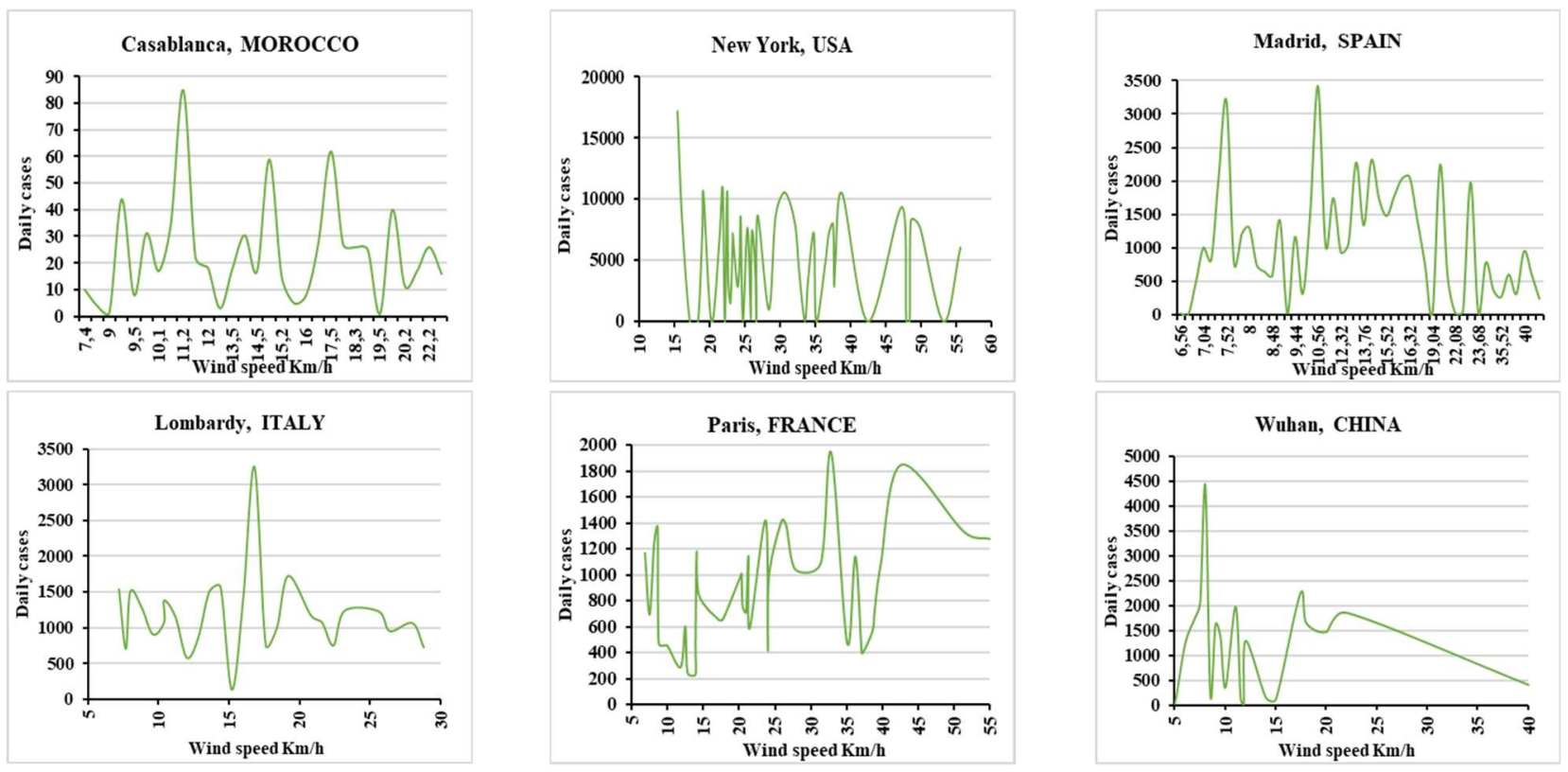

Figure 6. Influence of wind speed on the number of daily cases infected.

Figure 7 shows that the population density factor highly affects the daily number of COVID-19 infections with a rate of $90 \%$ compared to the other parameters under study. Furthermore, the speed of COVID-19 spread was faster at the area which is highly populated as NewYork and Wuhan, and the quarantine was the only solution to reduce the progression of COVID-19 infections' evolution (Figures $\mathrm{A} 2$ and $\mathrm{A} 3$ in Appendix A). 


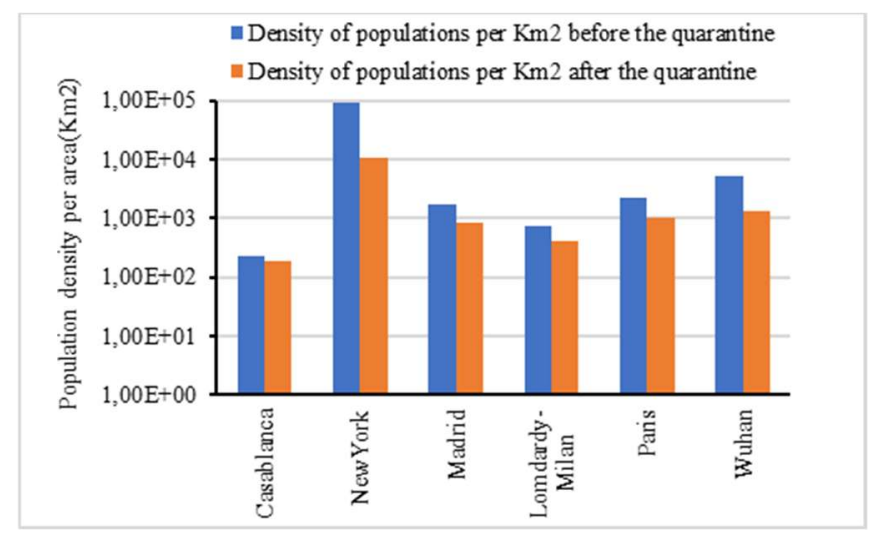

Figure 7. Average Population density before and after the quarantine of across the cities under study [21].

Based on those results, the previous system of differential equations (3), (4) and (5) could be rewritten as:

$$
\left\{\begin{array}{l}
\frac{d S}{d t}=-(a+\gamma) S\left(t-t_{i p}\right) \cdot I\left(t-t_{i p}\right) \\
\frac{d I}{d t}=(a+\gamma) S\left(t-t_{i p}\right) \cdot I\left(t-t_{i p}\right)-(b+\gamma) I(t) \\
\frac{d R}{d t}=(b+\gamma) I(t)
\end{array}\right.
$$

While, $\gamma$ is the proportion in which wind speed contributes in reducing the number of susceptibles then infections.

Furthermore, the subtracted time-period tip from $t$ time, means that an infected patient could infect a susceptible or more after an incubation period of $t_{i p}=5.75$ days.

The population density factor affects the evolution of infections by $90 \%$, while the wind speed affects it by only $10 \%$, so $\gamma<$ a, then, we estimated that $\gamma \simeq \frac{a}{9}$. So, these conditions could be described mathematically as follow:

$$
\left\{\begin{array}{l}
\text { if } S>\frac{a+\gamma}{b+\gamma} \text { so } \frac{d I}{d t}>0 \\
\text { we say that the COVID19 epidemic grows } \\
\text { if } S<\frac{a}{b} \text { so } \frac{d I}{d t}<0 \\
\text {, we say that the COVID19 epidemic shrinks }
\end{array}\right.
$$

Where, the coefficient $\frac{a+\gamma}{b+\gamma}$ presents the threshold and the initial conditions of S0, I0 and R0 presents successively the proportions of susceptibles, infected cases and recovered patients at $\mathrm{t} 0$ in each city, while, $\mathrm{a}=0.35, \mathrm{~b}=0.111$, and $\gamma=0.04$.

Figure 8 shows the comparison between SIR model where only population density was taken into account and our estimated model where we have implemented simultaneously the impact of wind speed and population density factors in order to estimate their effects on daily COVID-19 infections' evolution. 

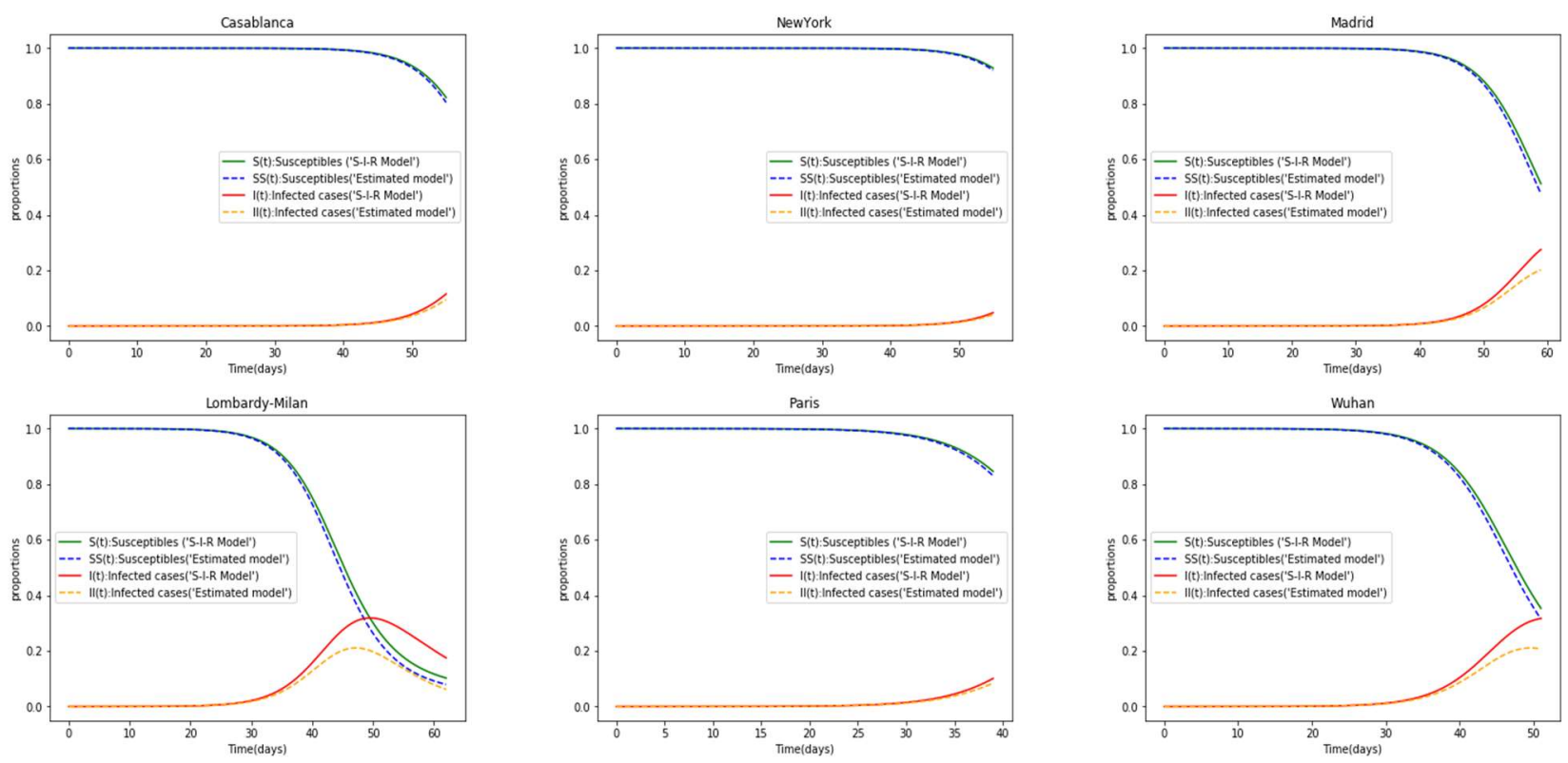

Figure 8. Comparison between SIR model and the proposal mathematical model.

\section{Conclusion}

The objective of this work is to study the impact of climate parameters, altitude, and population density factors on the daily number of COVID-19 infections within 85 days, between the $1^{\text {st }}$ February the $25^{\text {th }}$ April 2020 around six cities (Casablanca, Paris, Madrid, Lombardy-Milan, New York and Wuhan). The main results of this research showed that:

- The temperature, the humidity and the altitude parameters have no impact on daily COVID-19 infections' evolution.

- For an average wind speed greater than $25 \mathrm{~km} / \mathrm{h}$, the number of COVID-19 infections is slightly decreased with an approximate rate of $10 \%$.

- Population density has a significant impact on the daily COVID-19 spread with a rate of $90 \%$.

Based on this study, a mathematical model is proposed in which we have considered simultaneously the wind speed and the population density effects on the daily COVID-19 infections' evolution, consequently, in our estimated model the number of daily susceptibles and infections has slightly decreased compared to presented S-I-R model.

Author Contributions: Conceptualization, Rachid LAGTAYI and Lamya LAIRGI; Data curation, Rachid LAGTAYI and Lamya LAIRGI; Formal analysis, Rachid LAGTAYI and Lamya LAIRGI; Investigation, Abdelmajid DAYA and Ahmed KHOUYA; Project administration, Rachid LAGTAYI and Lamya LAIRGI; Supervision, Abdelmajid DAYA and Ahmed KHOUYA.

Funding: This research received no external funding.

Acknowledgments: We would like to thank every single author for her/his contribution to achieve this work.

Conflicts of Interest: The authors declare no conflict of interest.

\section{Appendix A}



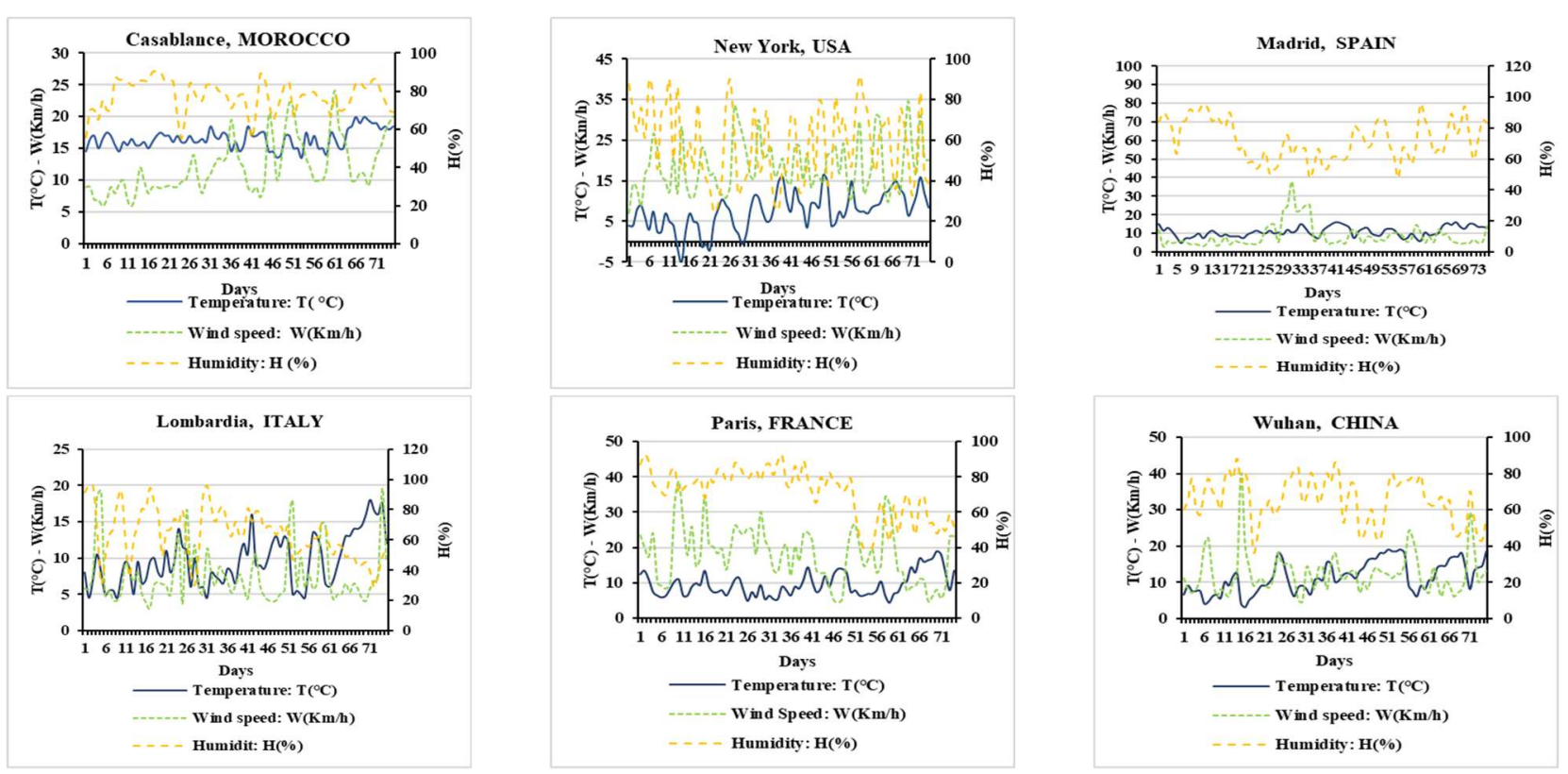

Figure A1. Climate conditions changes across the studied cities between January 23 and April 25, 2020.

Table 1. Climate data of the sixth cities under study.

\begin{tabular}{|c|c|c|c|c|c|c|}
\hline & \multicolumn{2}{|c|}{ Average temperature } & \multicolumn{2}{|c|}{ Average humidity } & \multicolumn{2}{|c|}{ Average wind speed } \\
\hline & Minimal & Maximal & Minimal & Maximal & Minimal & Maximal \\
\hline New York & $-0.5^{\circ} \mathrm{C}$ & $16.5^{\circ} \mathrm{C}$ & $24.5 \%$ & $91.8 \%$ & $11.2 \mathrm{~km} / \mathrm{h}$ & $55.7 \mathrm{~km} / \mathrm{h}$ \\
\hline Lombardy-Milan & $4.5^{\circ} \mathrm{C}$ & $19.3^{\circ} \mathrm{C}$ & $28.7 \%$ & $96 \%$ & $4.96 \mathrm{~km} / \mathrm{h}$ & $32 \mathrm{~km} / \mathrm{h}$ \\
\hline Paris & $4.5^{\circ} \mathrm{C}$ & $19^{\circ} \mathrm{C}$ & $40 \%$ & $93 \%$ & $6.88 \mathrm{~km} / \mathrm{h}$ & $55 \mathrm{~km} / \mathrm{h}$ \\
\hline Wuhan & $3{ }^{\circ} \mathrm{C}$ & $19^{\circ} \mathrm{C}$ & $37 \%$ & $87 \%$ & $6 \mathrm{~km} / \mathrm{h}$ & $29 \mathrm{~km} / \mathrm{h}$ \\
\hline
\end{tabular}
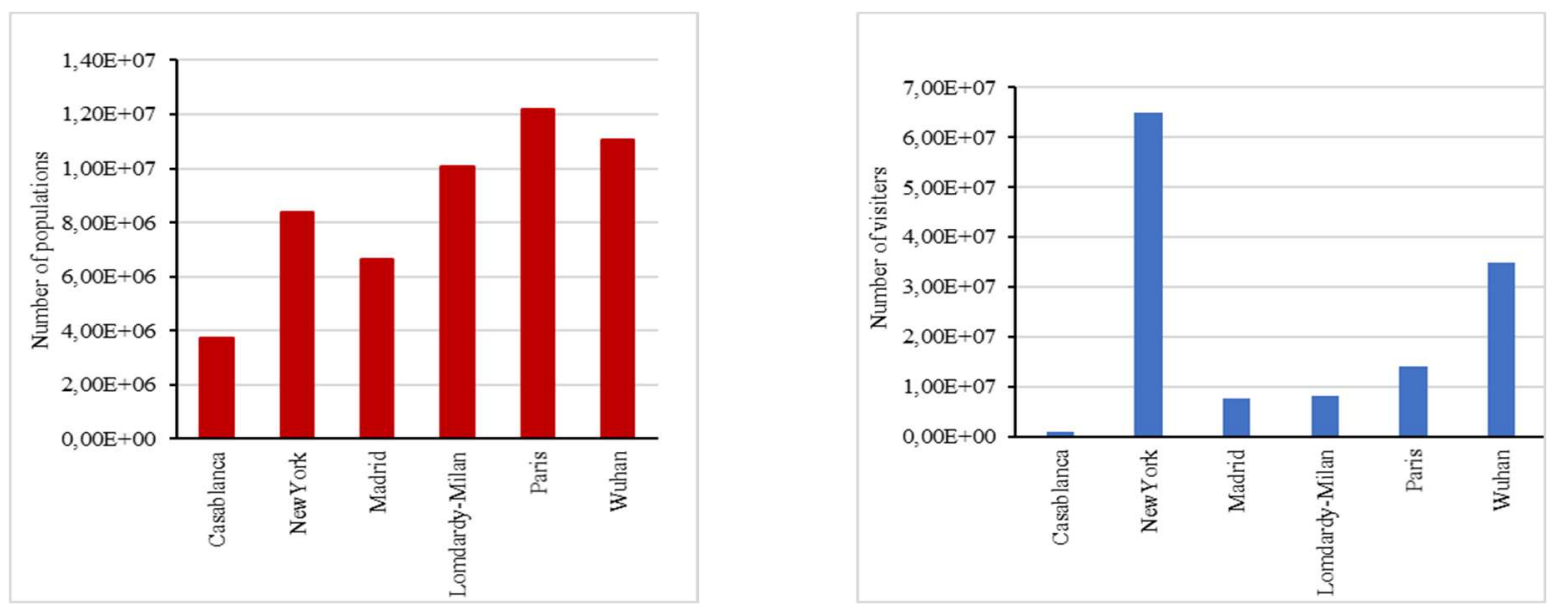

Figure A2. Average annual population density and visitors across the six cities under study [11] . 

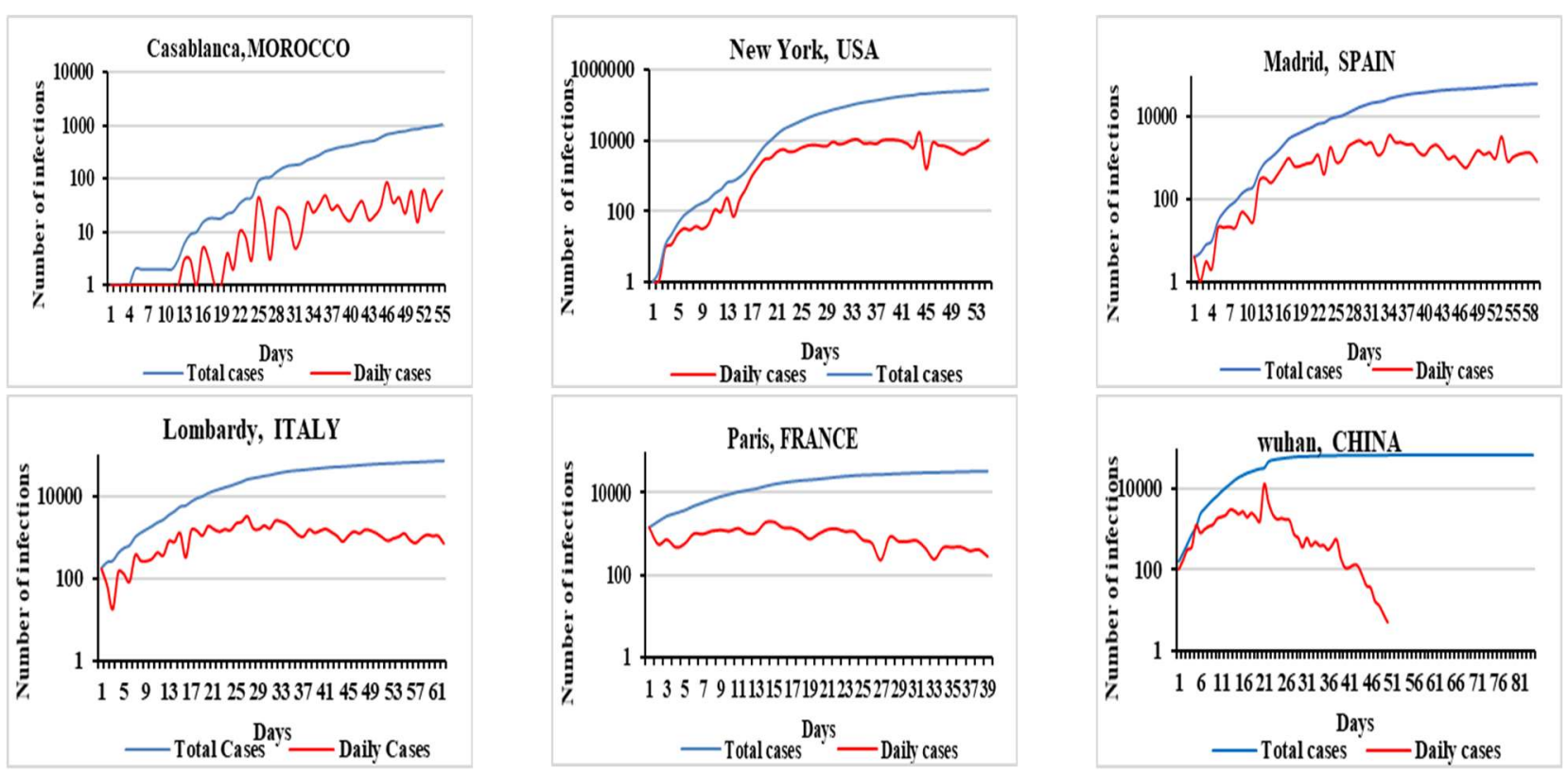

Figure A3. Evolution of daily and total COVID-19 infections over time (days) with a logarithmic scale [12]-[17] . 
Appendix B
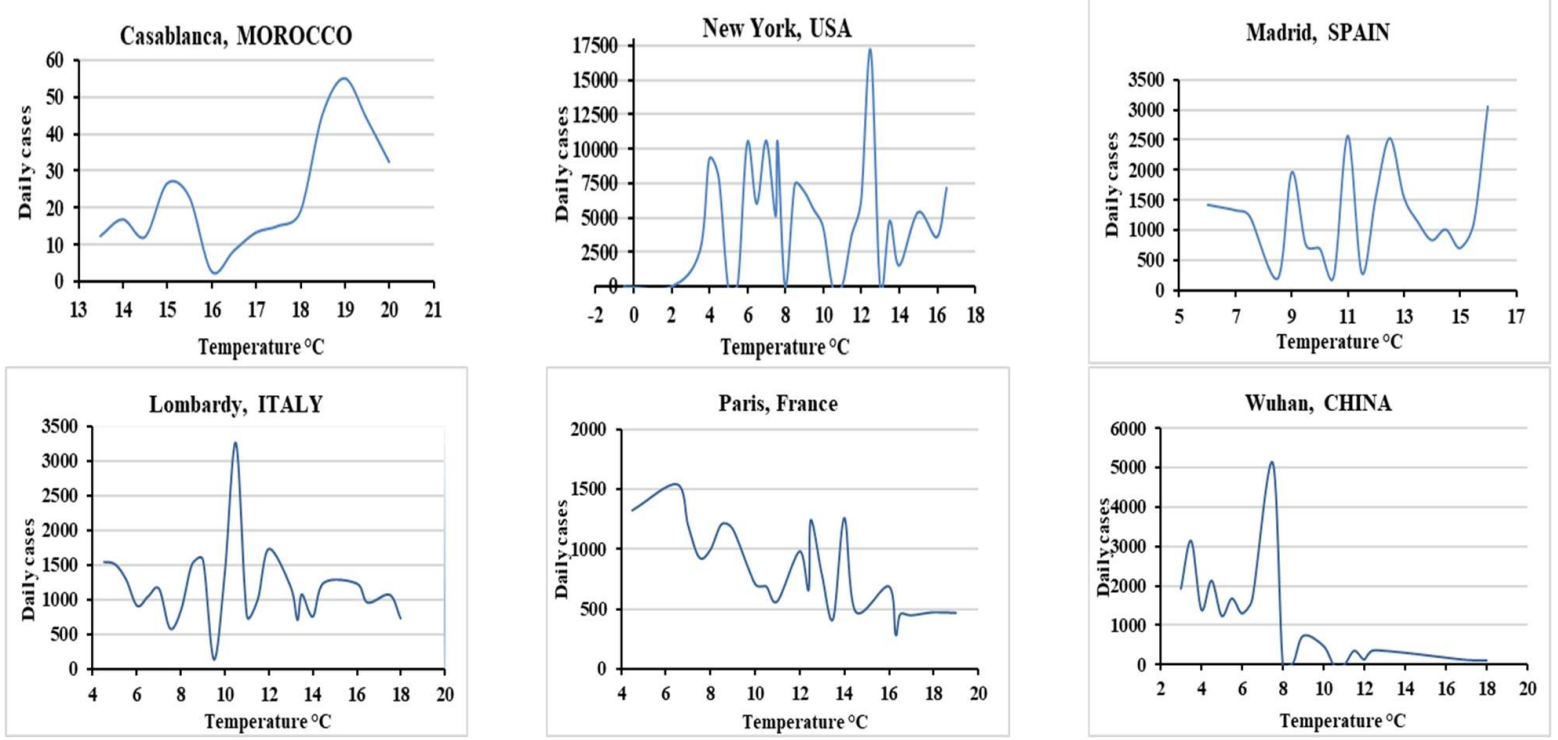

Figure B4. Influence of temperature on the daily number of COVID-19 infected cases.
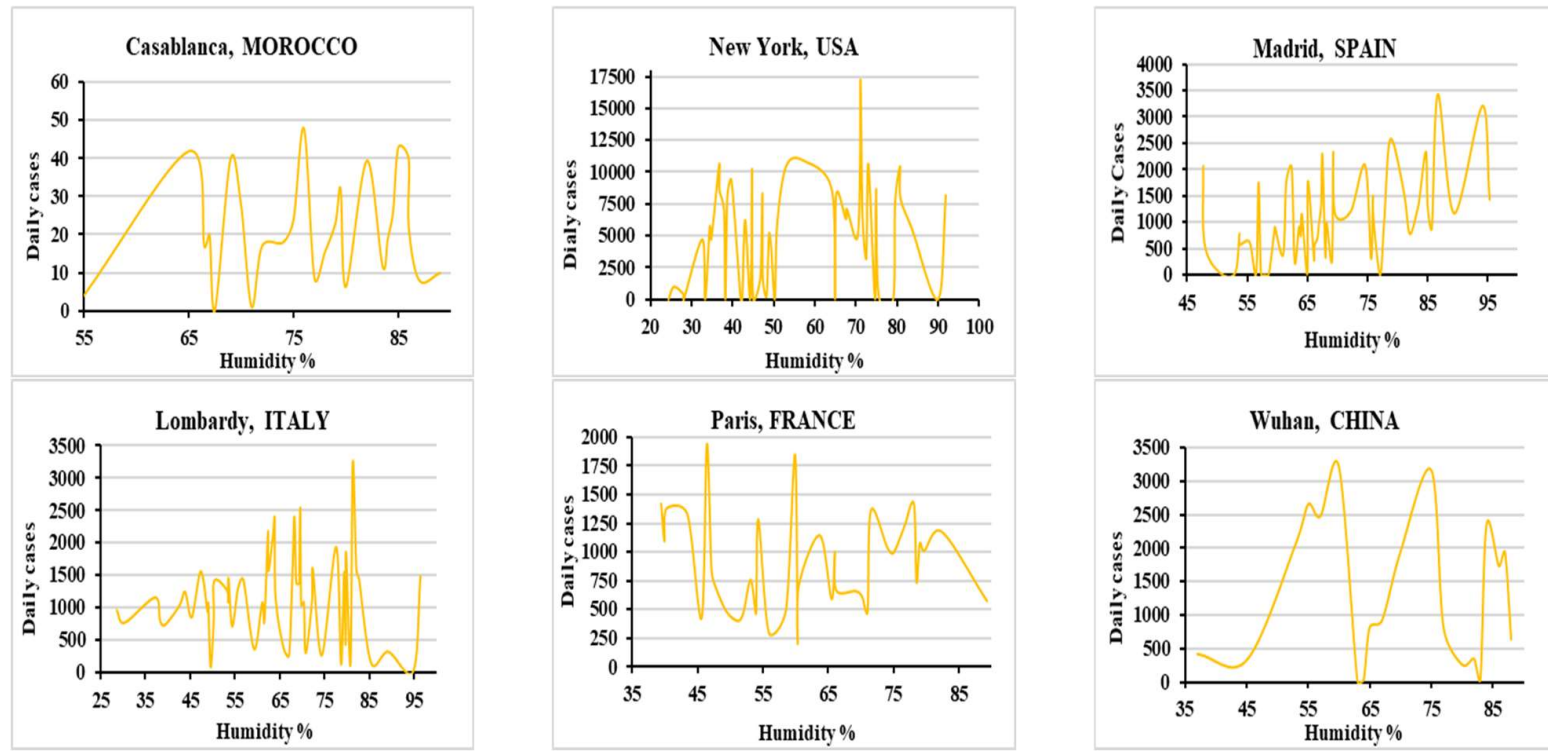

Figure B5. Average humidity impact on the daily number of COVID-19 infections. 


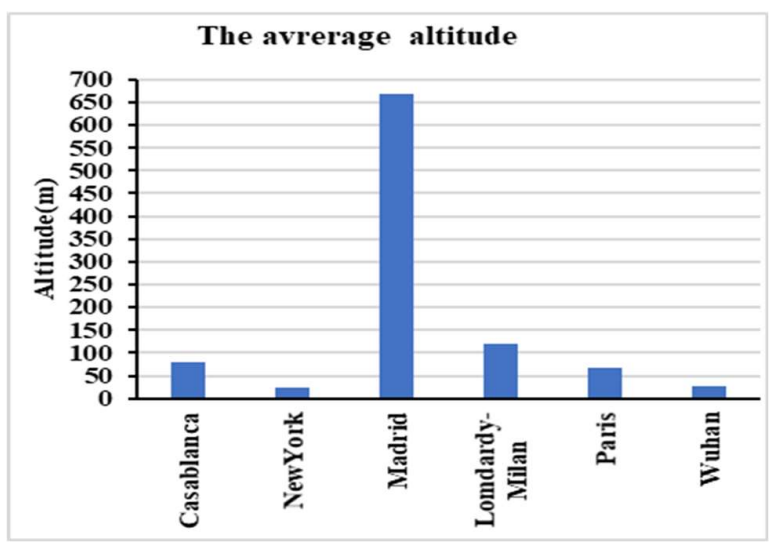

Figure B6. Average altitude of the studied cities [22].

\section{References}

[1] T. Lupia, S. Scabini, S. Mornese Pinna, G. Di Perri, F. G. De Rosa, and S. Corcione, “2019 novel coronavirus (2019-nCoV) outbreak: A new challenge," Journal of Global Antimicrobial Resistance, vol. 21, pp. 22-27, Jun. 2020, doi: 10.1016/j.jgar.2020.02.021.

[2] S. Chen, J. Yang, W. Yang, C. Wang, and T. Bärnighausen, "COVID-19 control in China during mass population movements at New Year," The Lancet, vol. 395, no. 10226. Lancet Publishing Group, pp. 764-766, 07-Mar-2020, doi: 10.1016/S01406736(20)30421-9.

[3] M. R. Berenbaum, "PNAS and the pandemic." Proc. Natl. Acad. Sci., 2020.

[4] A. Trilla, G. Trilla, and C. Daer, “The 1918 'Spanish Flu' in Spain,” Clinical Infectious Diseases, vol. 47, no. 5, pp. 668-673, Sep. 2008, doi: 10.1086/590567.

[5] C. Wang, P. W. Horby, F. G. Hayden, and G. F. Gao, “A novel coronavirus outbreak of global health concern,” The Lancet, vol. 395, no. 10223, pp. 470-473, 2020.

[6] D. S. Hui et al., "The continuing 2019-nCoV epidemic threat of novel coronaviruses to global health - The latest 2019 novel coronavirus outbreak in Wuhan, China," International Journal of Infectious Diseases, vol. 91. Elsevier B.V., pp. 264-266, 01-Feb2020, doi: 10.1016/j.ijid.2020.01.009.

[7] World Health Organisation, “WHO Coronavirus Disease (COVID-19)," 2020. [Online]. Available: https://covid19.who.int/. [Accessed: 30-Apr-2020].

[8] M. Şahin, "Impact of weather on COVID-19 pandemic in Turkey," Science of the Total Environment, vol. 728, p. 138810, Aug. 2020, doi: 10.1016/j.scitotenv.2020.138810.

[9] M. M. Sajadi, P. Habibzadeh, A. Vintzileos, S. Shokouhi, F. Miralles-Wilhelm, and A. Amoroso, "Temperature and Latitude Analysis to Predict Potential Spread and Seasonality for COVID-19," SSRN Electronic Journal, Mar. 2020, doi: 10.2139/ssrn.3550308.

[10] C. R. Wells et al., "Impact of international travel and border control measures on the global spread of the novel 2019 coronavirus outbreak," Proceedings of the National Academy of Sciences, vol. 117, no. 13, pp. 7504-7509, 2020.

[11] S. B. Friedrich Schwandt, “• Statista S. A. R. L.," 2020. [Online]. Available: https://www.statista.com/. [Accessed: 05-Mar-2020].

[12] Health Care ministry of Morocco, “Statistiques et cas coronavirus au maroc," 2020. [Online]. Available: http://www.covidmaroc.ma/Pages/AccueilAR.aspx. [Accessed: 30-Apr-2020].

[13] NewYork Governor, “New York State Government,Oficial Website," 2020. [Online]. Available: http://en.nhc.gov.cn/news.html. [Accessed: 30-Apr-2020].

[14] E. Ministerio de Sanidad, “El coronavirus, en datos casos en España y el mundo," 2020. [Online]. Available: https://www.eldiario.es/sociedad/mapa-evolucion-coronavirus-expansion-Espana.html. [Accessed: 30-Apr-2020].

[15] Flourish, "Coronavirus in Italy: Updated Map and Case Count," $2020 . \quad$ [Online]. Available: https://lab24.ilsole24ore.com/coronavirus/en/. [Accessed: 30-Apr-2020].

[16] S. NIRASAY, “Statistiques et cas Coronavirus COVID-19 Île-de-France," $2020 . \quad$ [Online]. Available: https://www.cascoronavirus.fr/. [Accessed: 30-Apr-2020].

[17] N. H. C. of the PRC, "Novel coronavirus cases in China," 2020. [Online]. Available: http://en.nhc.gov.cn/. [Accessed: 30-Mar2020].

[18] R. Pung et al., "Investigation of three clusters of COVID-19 in Singapore: implications for surveillance and response measures," The Lancet, vol. 395, no. 10229, pp. 1039-1046, Mar. 2020, doi: 10.1016/S0140-6736(20)30528-6.

[19] C. You et al., "Estimation of the time-varying reproduction number of COVID-19 outbreak in China," International Journal of Hygiene and Environmental Health, vol. 228, p. 113555, May 2020, doi: 10.1016/j.ijheh.2020.113555.

[20] C. C. McCluskey, "Complete global stability for an SIR epidemic model with delay-distributed or discrete," Nonlinear Analysis: Real World Applications, vol. 11, no. 1, pp. 55-59, 2010. 
[21] C. Baron, “Demographics Statista," 2020. [Online]. Available: https://www.statista.com/markets/411/topic/446/demographics/. [Accessed: 01-Mar-2020].

[22] O. SAS, “Topographic maps, elevation, relief," 2020. [Online]. Available: https://en-gb.topographic-map.com/. [Accessed: 05Mar-2020]. 